\title{
Improved rotorod performance and hyperactivity in mice deficient in a protein repair methyltransferase
}

\author{
Ryan Vitali, Steven Clarke* \\ Department of Chemistry and Biochemistry, Molecular Biology Institute, UCLA, 607 Charles E. Young Drive East, \\ Los Angeles, CA 90095-1569, USA
}

Received 11 September 2003; received in revised form 17 November 2003; accepted 17 November 2003

Available online 29 December 2003

\begin{abstract}
The protein L-isoaspartate (D-aspartate)- $O$-methyltransferase participates in the repair of age-induced protein damage by initiating the conversion of abnormal aspartyl residues within proteins to normal L-aspartyl residues. Previous studies have shown that mice deficient in the gene encoding this enzyme (Pcmtl-/-) accumulate damaged proteins, have altered levels of brain $S$-adenosylmethionine (AdoMet) and $S$-adenosylhomocysteine (AdoHcy), and suffer from epileptic seizures that result in death at an average age of about 42 days. In this study, we found that the behavior of $P c m t 1-/-$ mice is abnormal in comparison to their wild-type $(P c m t 1+/+)$ and heterozygous $(P c m t 1+/-)$ littermates in two standard quantitative behavioral assays - the accelerating rotorod and the open-field test. On the accelerating rotorod, we found $P \mathrm{cmt} I-/-$ mice actually perform significantly better than their heterozygous and wild-type littermates, a situation that has only been infrequently described in the literature and has not been described to date for epilepsy-prone mice. The Pcmt1-/- mice show, however, hyperactivity in the open-field test that becomes more pronounced with age, with a partial habituation with time in the chamber. Additionally, these mice demonstrate a strong thigmotaxic movement pattern. We present evidence that these phenotypes are not related to the alterations of the AdoMet/AdoHcy ratio in the brain and thus may be a function of the accumulation of damaged proteins. These results implicate a role for this enzyme in motor coordination and cerebellum development and suggest the importance of the function of the repair methyltransferase in hippocampal-dependent spatial learning.
\end{abstract}

(c) 2003 Elsevier B.V. All rights reserved.

Keywords: Rotorod; Hyperactivity; Epilepsy; Repair methyltransferase

\section{Introduction}

Proteins undergo a variety of cellular processes in the aging process that can lead to damage and decreased enzymatic efficiency [3]. One common type of damage is the isomerization and racemization of L-asparaginyl and L-aspartyl residues within the protein's polypeptide backbone $[7,23]$. The resulting isoaspartyl and $\mathrm{D}$-configuration residues can alter the structure and function of the protein $[10,13,22,31]$. The presence of these altered residues in the beta-amyloid peptide may contribute to the pathology seen in Alzheimer's disease [24,28].

The importance of preventing the accumulation of proteins containing such damage is demonstrated by the presence in most cells of a highly conserved repair enzyme, the L-isoaspartyl (D-aspartyl)-O-methyltransferase [3]. This en-

\footnotetext{
* Corresponding author. Tel.: +1-310-825-8754; fax: +1-310-825-1968.

E-mail address: clarke@mbi.ucla.edu (S. Clarke).
}

zyme can initiate the reversal of L-isoaspartyl damage utilizing $S$-adenosyl-L-methionine (AdoMet) as a methyl donor to form an L-isoaspartyl methyl ester. This methyl ester spontaneously forms a mixture of proteins containing either the damaged L-isoaspartyl residue or the correct L-aspartyl form [14]. Repeated methylation and demethylation cycles drive the reaction to the normal L-aspartyl form. A similar pathway can result in the conversion of D-aspartyl residues to L-aspartyl and D-isoaspartyl residues [19]. This repair pathway helps to maintain the proper structure of proteins to provide for their function and stability.

While the role of this methyltransferase in L-isoaspartyl repair in vitro is clear, its physiological importance is less clear. The repair function of the enzyme implicated its likely involvement in cellular aging pathways. To study this pathway in mice, the single gene encoding this enzyme (Pcmt 1 ) has been disrupted and knockout mice obtained [16,30]. However, the long-term effects of isoaspartyl accumulation with age are obscured because Pcmtl-I- mice unexpect- 
edly display a phenotype of progressive epilepsy resulting in their death at an average of 42 days of age $[5,15,16,30]$. EEG analysis revealed that $P c m t 1-/-$ mice display abnormal electrical activity approximately $50 \%$ of the time monitored, even when they are not overtly seizing [15]. Several other secondary phenotypes were also observed including reduced weight $[16,30]$, sexual impotency or sterility $[2,15]$ and kyphosis of the spine [12]. Treating Pcmt1-/- knockout mice with a combination of the antiepileptic drugs valproic acid and clonazepam restored normal growth and extended the life span, but to only about 80 days [15]. Neuron-specific rescue of the $P c m t 1-/-$ mice with a transgenic methyltransferase cDNA can, however, extend the life span to about 200 days $[20,25]$.

To understand the phenotypes of Pcmtl-/- mice, it has generally been assumed that the loss of the repair enzyme results in the accumulation of damage in a variety of proteins leading to the neural impairment seen $[15,16,30]$. Tubulin [18], synapsin 1 [25], and amyloid-beta peptide $[24,28]$ have all been identified as potential candidates for isoaspartyl accumulation leading to loss of function. However, the loss of the repair enzyme has also been shown to alter the concentrations in brain of its small molecule substrates AdoMet and S-adenosyl-L-homocysteine (AdoHcy) [5]. It is thus possible that the increased AdoMet/AdoHcy ratio that accompanies the loss of Pcmt1 may also contribute to the Pcmt1-I- mutant seizure phenotype. Lower brain AdoHcy concentrations may stimulate epileptic behavior because this metabolite appears to be an endogenous neural inhibitor. Evidence supporting this theory includes the anticonvulsant effect of AdoHcy [6] and the fact many common antiepileptic drugs including valproate [29], phenobarbital [1], and diazepam [9] can elevate AdoHcy levels.

Subsequent studies aimed at determining Pcmt1's role in the brain pointed to hippocampal functions $[12,18]$. Specifically, the CA3 region of Pcmt1-/- mutant mice was found to degenerate [12]. Pcmt1-/- mice possibly undergo a kindling effect induced from the hyperexcitability of their epileptic activity [26]. Several behavioral tests have also been performed. Pcmt1-/- mice exhibit impaired spatial learning in the Morris water maze, decreased anxiety in the elevated plus maze, and impaired short-term memory in a context based avoidance test [12]. Unfortunately, these tests employed harsh procedures (i.e., shocking and swimming), which may induce epileptic episodes in the mutants and thus bias the results.

The goal of this study was to first examine Pcmt1-/performance in two common non-stressful behavioral tests that do not invoke electric shock, food deprivation, or swimming to demonstrate their potential as non-lethal measures of the Pcmtl-/- mutant's impairment. The accelerating rotorod and the open-field test were chosen. Once distinctive phenotypes were identified we attempted to mitigate them through a low-folate diet aimed at altering the Pcmt1-/mice's AdoMet/AdoHcy ratio.

\section{Materials and methods}

\subsection{Colony maintenance and genotyping}

The Pcmt1-I- mice used for these experiments were previously generated [16]. The strain is approximately $50 \%$ C57BL/6 and 50\% 129/SvJae and is highly inbred by brother-sister matings. A breeding colony was established at the UCLA Behavioral Testing Core facility and maintained under a $12 \mathrm{~h} / 12 \mathrm{~h}$ light/dark cycle (light on from 06:00 to 18:00 h). Pcmt1+/- mice were bred yielding litters composed of $P c m t 1+/+, P c m t 1+/-$, and $P c m t 1-/-$ pups in the expected Mendelian ratios. The pups were weaned at 22-23 days of age and separated based on sex into groups of three to four mice per cage with a random assortment of genotypes. Individual mouse genotypes were determined by PCR amplification of tail DNA. Two primer sets were used for amplification. The first set included 5'-ACCCTCTTCCCATCCACATC- $3^{\prime}$ and $5^{\prime}$-GCAGCGACGGCAGTAACAG- ${ }^{\prime}$ and was used to amplify a 405 base pair wild-type product within the Pcmtl exon 1. The second set included 5'-GCACGAGGAAGCGGTCAGCCCATTC- ${ }^{\prime}$ and $5^{\prime}$-CGCATCGAGCGAGCACGTACTCGG- $3^{\prime}$ that amplified a 310 base pair product within the neomycin cassette interrupting the $P c m t 1$ gene.

Water and a commercial rodent chow in pellet form (LabDiet 5001, Purina Mills) were provided without restriction to the animals on the standard diet. For mice maintained on a low-folate diet, this standard chow was replaced by a \#517894 diet from Dyets Inc. (Easton, PA). This diet (also in pellet form) is a modified Clifford L-amino acids rodent diet with $0.2 \mathrm{mg}$ of folate $/ \mathrm{kg}$ and $1 \%$ succinyl sufathiazole antibiotic.

\subsection{Rotorod testing}

Rotorod testing was done on a TSE Systems Rotorod System (SciPro Inc.). The apparatus consisted of a $20 \mathrm{~cm}$ raised drum $10 \mathrm{~cm}$ in circumference split into separate lanes to allow simultaneous testing of five mice. The drum's surface was covered with rubber matting to provide for enhanced grip for the mice. Mice were first weighed and then loaded on the rotorod at an initial speed of $5 \mathrm{rpm}$. This speed was maintained for $1 \mathrm{~min}$ to allow mice to become acclimated to the device. If mice fell during this period, they were replaced on the rotorod. After this initial loading phase, the rotorod was gradually accelerated from 5 to $60 \mathrm{rpm}$ over the course of $3 \mathrm{~min}$. A light-beam sensor located below each compartment on the drum recorded the time and rpm speed of the drum when a mouse fell from the device. In a few instances, mice would cling to the grip of the rotating drum rather than fall from it. When this occurred, the light-beam sensor was manually triggered when the mouse failed to resume normal performance after three consecutive revolutions. After all mice fell from the rotorod, the group was given a 4-min rest period and then reloaded on the device as before but without 
the 1-min acclimation period. Mice were tested again as described above, allowed to rest for $4 \mathrm{~min}$, and then tested a final time. All testing was done between 13:00 and 16:00 h. The experimenter was present in the room during the testing.

\subsection{Open-field analysis}

The open-field apparatus consisted of a $10.75 \mathrm{in} . \times$ 10.75 in. square Plexiglas chamber 8 in. high that tracked and recorded animal movement by infrared beam interruption patterns (ENV-510 model, MED Associates, Inc.) Simultaneous analysis of $P c m t 1-/-$ mice and their $P c m t 1+/-$ and Pcmt1-1- controls were performed using four chambers. Animal tracking in the $X Y$-plane was monitored through 16 evenly spaced infrared sensors. An additional photobeam detected movement 2 in. above the bottom of the apparatus to detect hind-leg vertical rearings by the mice on the $Z$-axis. Prior to testing, fecal pellets were removed and each chamber was then sprayed with an ammonia-based glass cleaner and wiped carefully to eliminate any residual odors from the mice. Cage mates were transported to the testing room and immediately loaded into their respective open-field chambers. Each trial consisted of one 10-min trial that was split into 10 individual 1-min periods for analysis purposes. Illumination was kept at a constant dim level slightly above a reading threshold. Background noise was provided via a small portable air conditioner located in the center of the testing units. The experimenter was not present in the room during the experiment. All testing was done between 16:00 and 19:00 h. For thigmotaxic behavioral analysis, the open-field's center was defined as the 8 in. $\times 8$ in. area in the middle of the apparatus.

\subsection{Plasma homocysteine analysis}

Blood plasma homocysteine (Hcy) levels were measured in Pcmtl+/+, Pcmtl+/-, and Pcmt1-/- littermates. Mice were fasted for $12 \mathrm{~h}$ prior to sample collection. Mice were anesthetized with isoflourane and blood was collected through retro-orbital bleeding with heparin-coated micro-hematocrit capillary tubes (Fisher Scientific, Catalog \# 22-362-566). Samples were immediately transferred into heparin-treated collection vials and placed on ice. The samples were spun at $1700 \times g$ for 3 min to pellet red blood cells and the plasma supernatant was collected for analysis. Plasma samples were shipped overnight on wet ice to Anticancer Inc. (San Diego, CA) for analysis using a previously published protocol [27].

\subsection{Mouse brain HPLC analysis}

High pressure liquid chromatography analysis of AdoMet and AdoHcy levels in whole mouse brain homogenates were done of mice sacrificed at 50 days of age by a previously described protocol [5].

\subsection{Statistical analysis}

Data were analyzed for repeated measure ANOVA and two-tailed $t$-tests using StatView version 5.0 software for the PowerPC.

\section{Results}

\subsection{Characterization of Pcmt1-/- mice on normal and low-folate diets}

Access to behavioral equipment necessitated the establishment of a second UCLA colony of Pcmt1-deficient mice. This colony was founded from previously inbred Pcmt $1+/-$ mice transferred from the Center for Health Sciences to a separate vivarium in Franz Hall. These Pcmt $1+/$ - mice were subsequently interbred to generate mice of various Pcmt 1 genotypes, but that were otherwise genetically identical, for behavioral testing. As shown in Fig. 1, we measured the life span of the Pcmt1-/- mice in this facility and found that $50 \%$ survival at 43 days, a similar time to those previously obtained in other studies $[5,15,16,31]$. There was only one death noted of PcmtI+I- and PcmtI+I+ mice before 200 days.

We detected a number of qualitative differences between the Pcmt1-I- and Pcmtl $+/+$ and Pcmt1+I- mice. Pcmt1-/- mice did not display the typical handling avoidance behavior seen in heterozygotes and wild-type animals such as congregating in cage corners and making evasive movements when cages were moved or mice were picked up. The methyltransferase-deficient mice also sometimes appeared to be unaware of their surroundings, and relatively motionless, even in the absence of any detectable seizure activity. Randomly occurring non-fatal seizures were frequently observed.

We also tested the survival of Pcmtl-I- mice on the low-folate diet described in Section 2. This diet was designed to test whether changes in the AdoMet/AdoHcy ratio in brain might affect behavioral changes (see below). Mice on the low-folate diet were found to live marginally longer than those on the standard diet, with a $50 \%$ survival time of 48 days (Fig. 1).

\subsection{Pcmt1-1- mice perform significantly better on the accelerating rotorod task than their Pcmt $1+/+$ and Pcmt1+/- littermates}

We first asked whether the loss of the protein repair gene function and the accompanying accumulation of damaged substrates and increased seizure activity would affect their ability to maintain their balance on an accelerating rotorod apparatus (Fig. 2). The rotorod was accelerated from 5 to $60 \mathrm{rpm}$ over $3 \mathrm{~min}$ as described in Section 2. In these experiments, mice were only tested once (three trials in one session) and thus our results give a measure of initial 


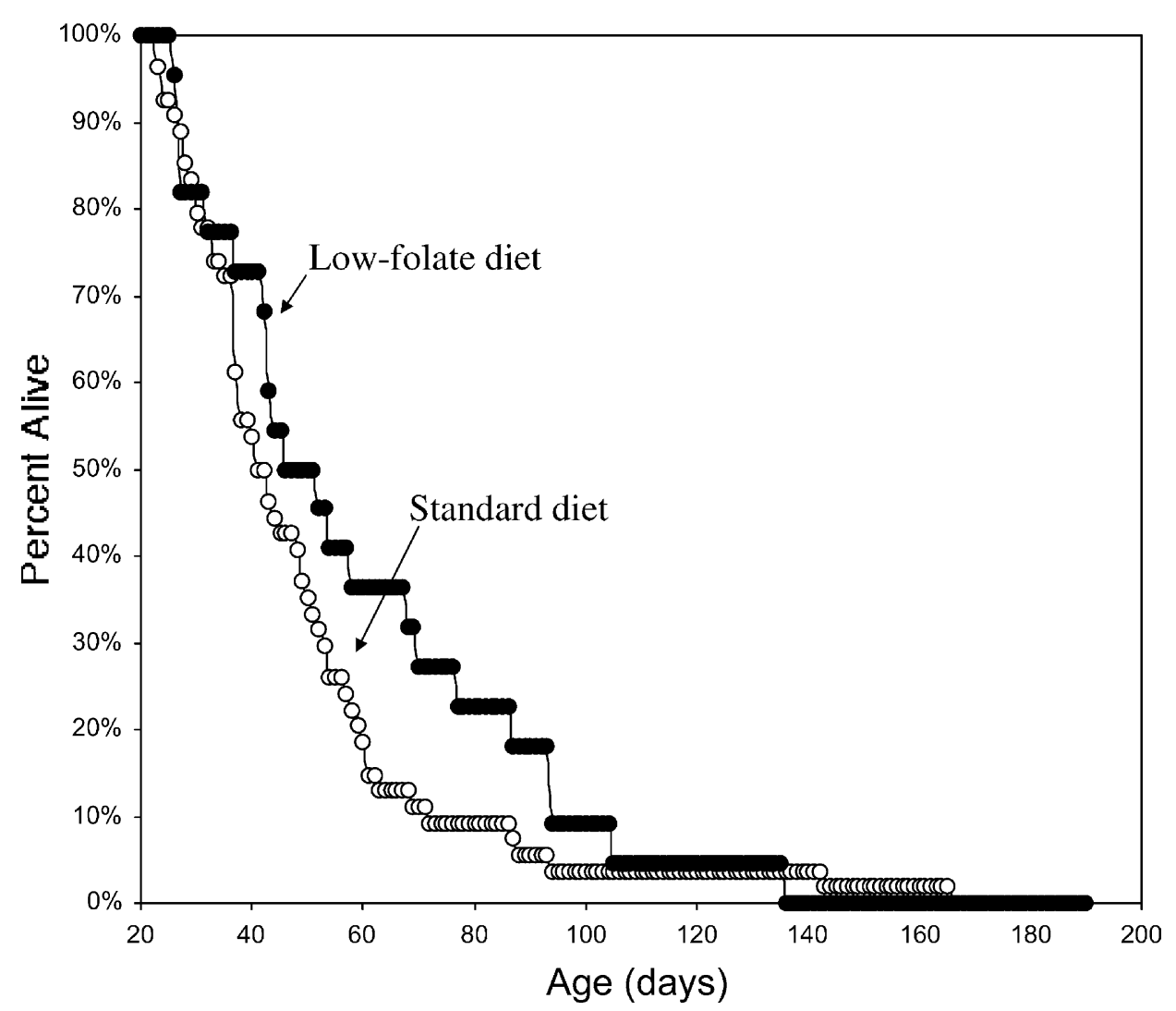

Fig. 1. Survival curve for Pcmt1-/- mice on normal and low-folate diet. All mice were weaned at $22-23$ days of age and housed randomly by sex in groups of three to four mice per cage. The survival curve depicted above includes Pcmt $1-1-$ mice $(n=54)$ fed a standard diet and Pcmt $1-/-$ diet fed a low-folate diet (described in Section 2) $(n=22)$ mice. All Pcmt $1+/-$ and Pcmt $1+/+$ littermates lived beyond the time period depicted on this graph.

motor coordination rather than motor learning. Surprisingly, the Pcmt1-1- mice performed significantly better than Pcmtl $+/+$ and Pcmtl+/- controls (Fig. 2).

This superior performance was all the more remarkable because Pcmt1-/- mice often spontaneously fell or jumped from the rod immediately after loading, a phenomenon not observed in their heterozygotes or wild-type littermates. However, once the loading period ended and the trial was started, the knockout mice were able to stay on the rotorod significantly longer (Fig. 2). In one instance, a Pcmt1-/mouse seized after the second trial and was not tested further. All other Pcmt1-/- mice were able to complete the trials. The small decrease in the Pcmtl-l- performance seen in the third trial may be attributed to the seizure activity of a few mice who became unstable at the end of the session, but were still included in the data (Fig. 2). The rotorod success of the Pcmtl-I- mice was apparently not due to their smaller size because we saw no correlation between weight and performance with any of the groups of mice. Additionally, we found no correlation with age.

\subsection{Pcmt1-/- mice exhibit thigmotaxic hyperactivity in the open-field apparatus that progresses with age}

Mice were tested in an open-field apparatus as described in Section 2. The average moving velocity, ambulatory episodes, the total distance traveled, vertical rearings, and a measure of grooming behavior (quantitated as stereotypic counts) were recorded for each minute of a 10-min trial. In Table 1, we show data averaged over the each 1-min period of the 10-min trial. Here, we found no large difference between Pcmt1-/-, Pcmt1+/-, and Pcmtl+/+ mice in their average moving velocity and stereotypic counts. However, we observed a significant nearly two-fold increase in the number of ambulatory episodes for the Pcmt1-/- knockout mice, and a corresponding two-fold increase in the distance traveled. We also found decreased vertical rearing for the knockout mice, but not at a statistically significant level (Table 1). This behavioral hyperactivity could not be attributed to faster locomotion as the average moving velocities of $P c m t 1-/-$ mice were in fact slightly slower than their $P c m t 1+/-$ littermates $(P=0.014)$. No significant differences between $P c m t 1+/+$ and $P c m t 1+/-$ mice were observed.

When we grouped mice by age, we found the hyperactivity of $P \mathrm{cmt} 1-\mathrm{I}-$ mice as measured by total distance traveled increased with the age of the mouse (Fig. 3). At 28-34 days of age, Pcmt1-/- mice open-field activity levels were about 55\% higher than their $P c m t 1+/+$ and $P c m t 1+/-$ controls. At approximately 35 days of age, a sharp increase in the Pcmt1-/- population's hyperactivity was observed, where the activity was almost three-fold higher. This rise was 


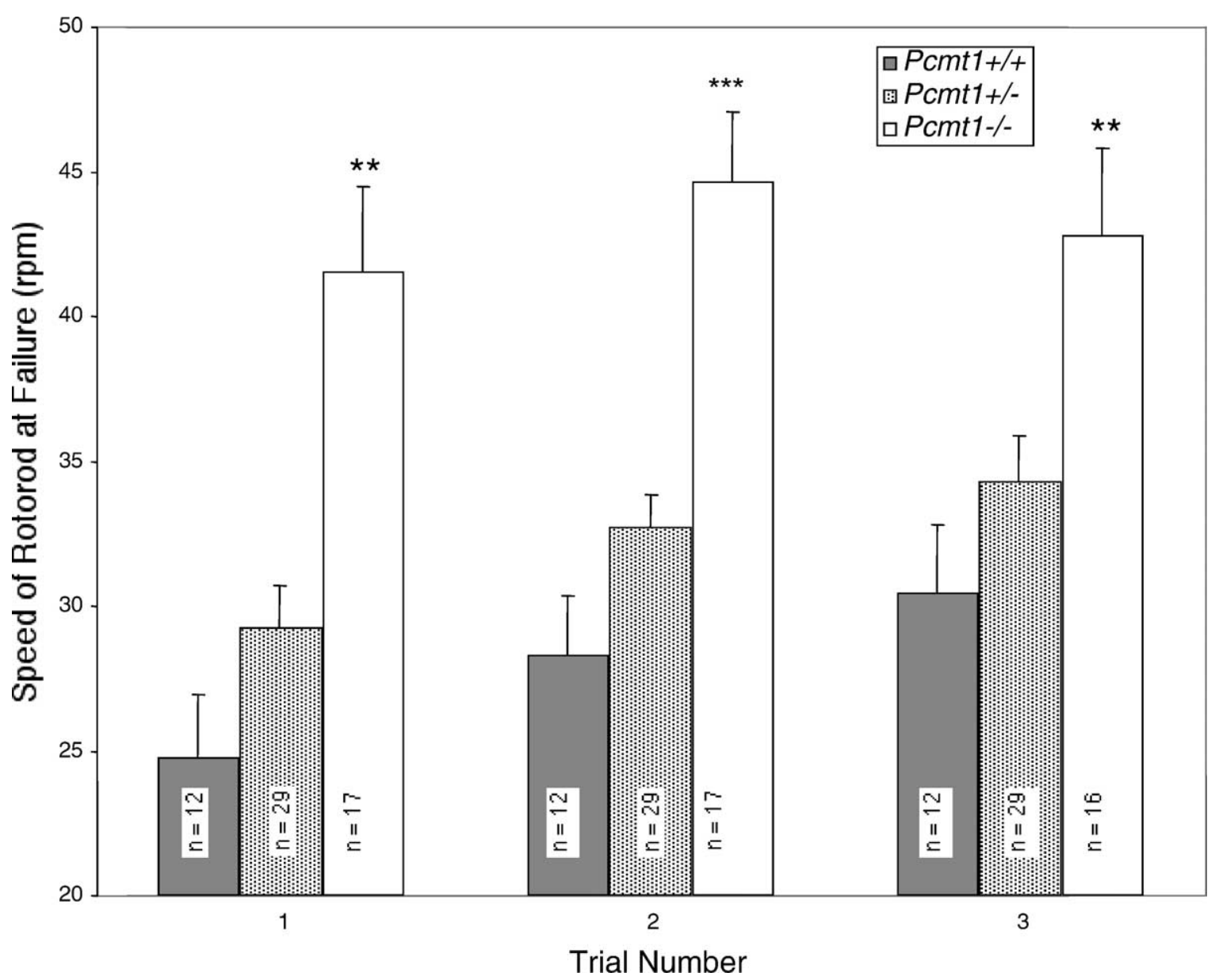

Fig. 2. Pcmt1-1- mice demonstrate improved coordination on the accelerating rotorod. Naïve mice between 28 and 48 days of age were tested on an accelerating rotorod that increased from 5 to $60 \mathrm{rpm}$ over the course of $3 \mathrm{~min}$. Each test consisted of three consecutive trials with 4-min rest periods between each trial. The number of animals of each genotype tested ranged from 12 to 29 and is shown at the bottom of each bar. One Pcmt1-/mouse was excluded from his third trial because a seizure occurred during the test. ${ }^{* * *} P<0.0001$ in comparison to both control groups. ${ }^{* *} P<0.005$ in comparison to both control groups. No significant difference between Pcmt $1+/+$ and $P c m t 1+/-$ mice was observed. Error bars represent standard the error of the mean.

statistically different from both their age-matched controls (Fig. 3) as well as when the activity of Pcmt1-l- between mice of 35 days and older was compared to mice of 28-34 days $(P<0.005)$. This increased hyperactivity persisted throughout their adulthood and often grew greater upon subsequent open-field exposures later in life (data not shown).
We next asked whether the observed hyperactivity in Pcmt1-/- mice was prevalent throughout the open-field exposure. When we examined each 1-min period of the 10-min trial, we found that the activity of the heterozygotes and wild-type mice did not change, but the hyperactivity of the Pcmt1-/- mice appeared to habituate (Fig. 4).

Table 1

Open-field behavior of wild-type and protein-repair-deficient mice maintained on a standard diet ${ }^{\mathrm{a}}$

\begin{tabular}{lccc}
\hline Measure of activity & Mouse genotype & & \\
\cline { 2 - 4 } in a 1-min period & Wild-type & Heterozygote & Repair-deficient \\
& $P c m t 1+/+(n=22)$ & $P c m t 1+/-(n=41)$ & $26.2 \pm 1.0$ \\
\hline Average moving velocity $(\mathrm{cm} / \mathrm{s})$ & $24.4 \pm 1.0$ & $7.0 \pm 0.5$ & $23.0 \pm 0.7$ \\
Ambulatory episodes & $6.7 \pm 0.6$ & $129 \pm 9$ & $12.3 \pm 1.0^{\mathrm{b}}$ \\
Distance traveled $(\mathrm{cm})$ & $125 \pm 10$ & $20.3 \pm 1.2$ & $254 \pm 23^{\mathrm{b}}$ \\
Vertical rearings & $19.3 \pm 1.5$ & $157 \pm 5$ & $17.2 \pm 1.1$ \\
Stereotypic counts & $153 \pm 7$ & $150 \pm 5$ \\
\hline
\end{tabular}

\footnotetext{
${ }^{a}$ Values are given \pm standard error of the mean.
}

${ }^{\mathrm{b}} P$-value $<0.0001$, when compared to wild-type and heterozygotes. 


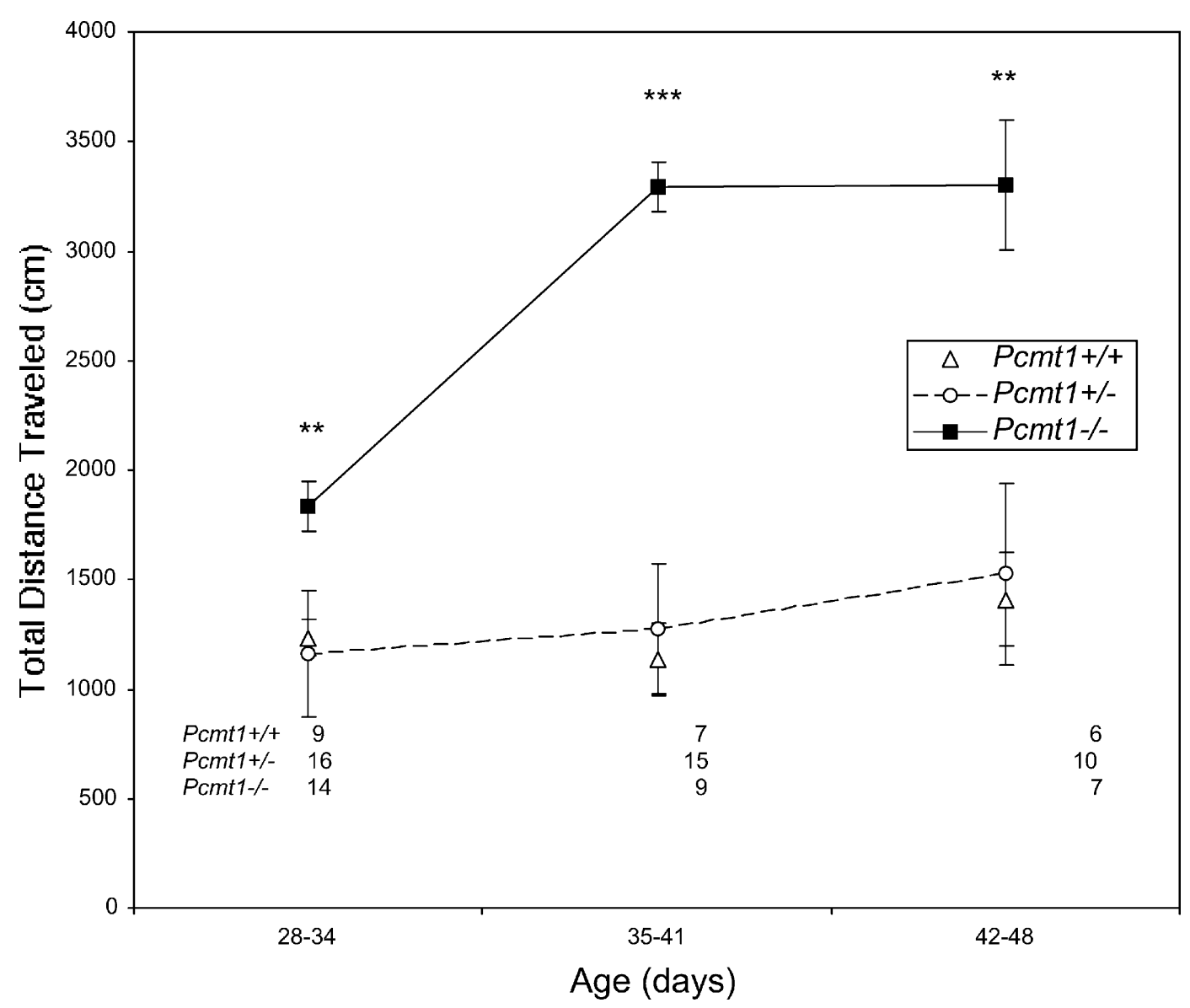

Fig. 3. Pcmt1-/- mice display increasing hyperactivity with age on an open-field test. The average distance traveled during the entire course of a 10-min open-field exposure is shown for each genotype for mice in three age groups. The number of mice tested of each genotype is shown at the bottom of the graph. Only naïve mice were tested in these experiments. The error bars represent the standard error of the mean. ${ }^{* *} P<0.01$ in comparison to Pcmt $1+/+$ and Pcmt $1+/$ - controls. ${ }^{* * *} P<0.0001$ in comparison to $P c m t 1+/+$ and $P c m t 1+/-$ controls.

Knockout mice were most hyperactive when initially entering the open field, and activity decreased steadily as they became more acclimated to the novel environment $(P<0.0001$ by repeated measure ANOVA analysis). However, their activity never dropped to the levels seen in their Pcmt $1+/-$ and Pcmtl+/+ siblings. An analysis of ambulatory episodes gave a similar result (data not shown). When the data was analyzed on a per minute basis, we now detected a statistically significant decrease in the number of vertical rearings of Pcmt1-I- mice compared to their heterozygote and wild-type siblings (Fig. 5). While all mice show an increase in the number of their vertical rearings during the entire trial $(P<0.0001)$, the $P c m t 1-/-$ mice increased at a significantly slower rate $(P<0.0001)$. There was no difference observed in the rate of increase between Pcmtl + / - and Pcmtl $+/+$ mice.

Comparing Pcmt1-/- mice's exploratory behavior patterns to those of $P c m t 1+/+$ and $P c m t 1+/-$ mice revealed that some knockouts exhibited severe thigmotaxic behavior (Fig. 6). While all mice initially tended to prefer the corners and edges of the open field versus the exposed center, most eventually ventured to the middle. Surprisingly, some
Pcmt1-/- mice strongly avoided the open field's center despite their hyperactivity. This prompted us to compare the time spent in the center of the open-field apparatus in the different genotypes (Fig. 7). While Pcmt $1+/+$ and Pcmt1+Imice showed a fairly proportional increase between total distance traveled and percent time in center, the proportion of time spent in the center for the Pcmt1-I- population was nearly independent of the total distance traveled. Thus, as Pcmt1-/- mice's activity increased, their exploration remained primarily thigmotaxic.

\subsection{Alterations in the brain AdoMet/AdoHcy ratio do not affect mouse behavior in rotorod and open-field testing}

After identifying these $P c m t 1-/-$ specific phenotypes we were interested in determining the effect of altering the brain AdoMet/AdoHcy ratio on their behavior in our assays. Pcmt1-/- mice have been shown to have an elevated ratio of AdoMet/AdoHcy in brain. This altered ratio has been postulated to be an important component of the seizure phenotype [5]. We thus wanted to ask whether the behavioral differences seen in the rotorod and open-field 


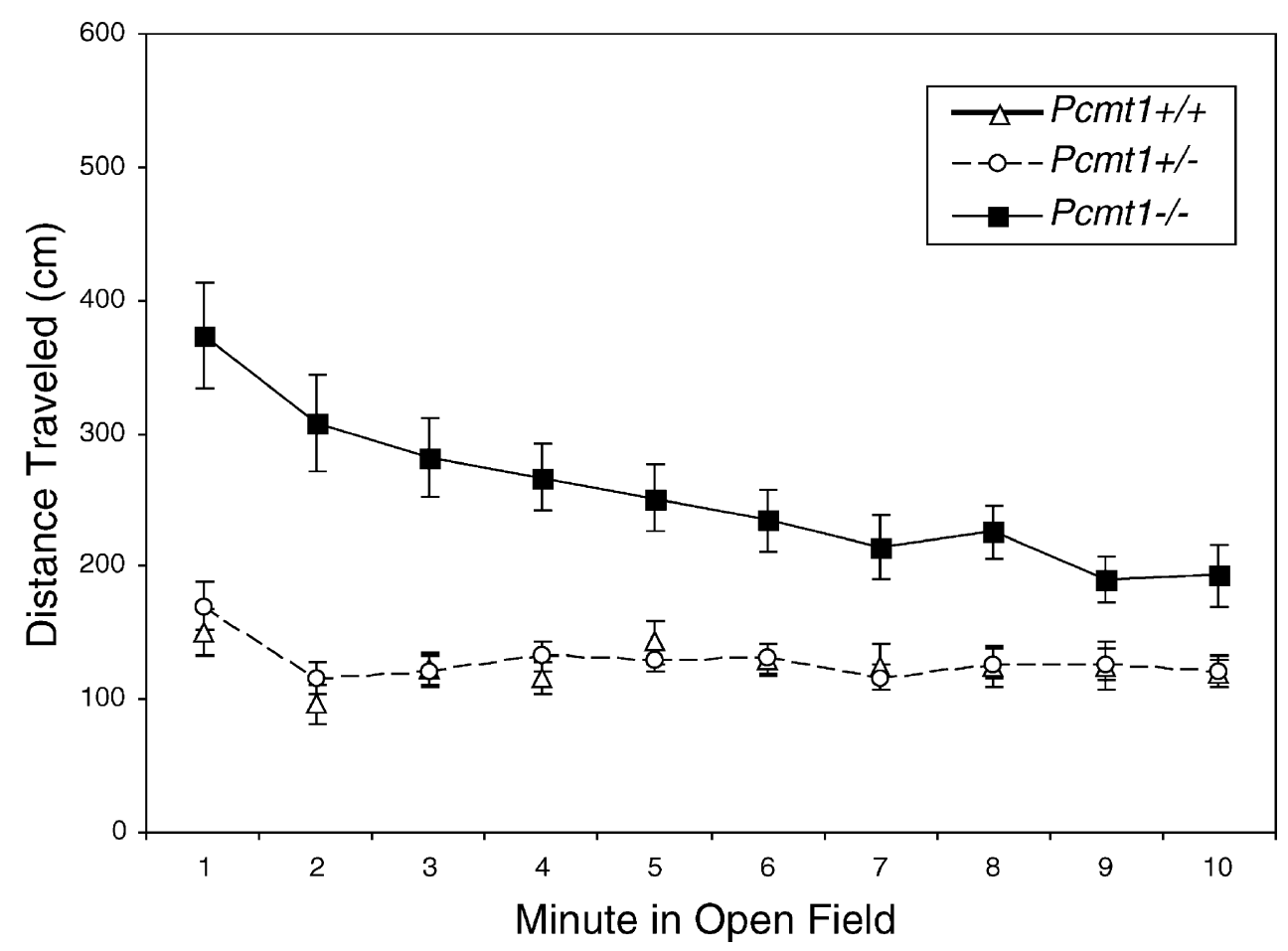

Fig. 4. Habituation of hyperactivity during open-field trials for naïve mice 28-48 days of age. The distance traveled in each minute of the 10-min open-field exposure is shown. The number of mice tested were 22,41 , and 31 for the $P c m t 1+/+, P c m t 1+/-$, and Pcmt $1-/-$ genotypes, respectively. The error bars represent the standard error of the mean.

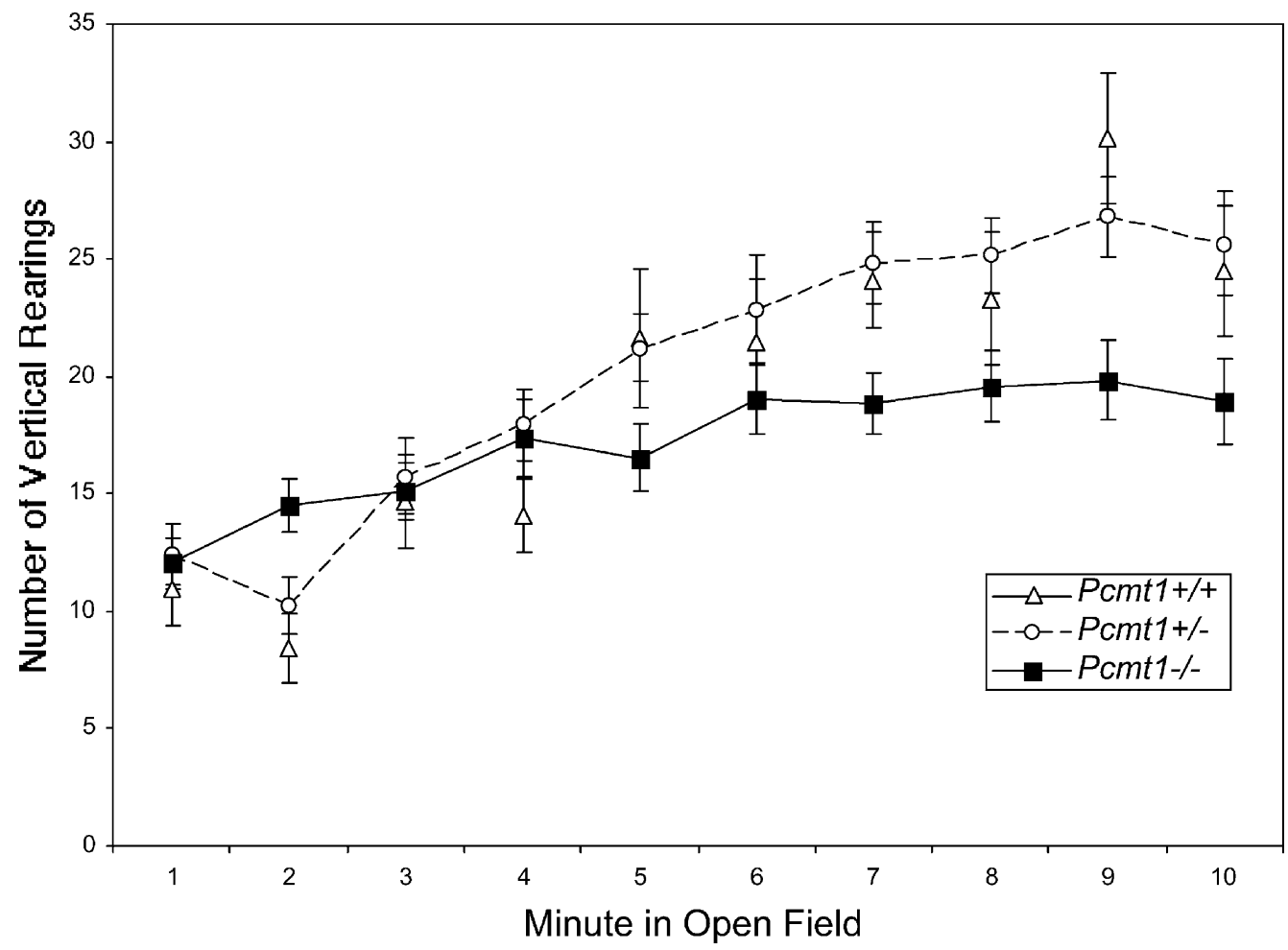

Fig. 5. Decreased vertical rearings in $P c m t 1-/-$ mice during open-field trials for naïve mice $28-48$ days of age. Vertical rearings were plotted during each successive minute of the open-field exposure. The number of mice tested were 22,41 , and 31 for the Pcmt $1+/+$, Pcmt $1+/-$, and Pcmt $1-/-$ genotypes, respectively. All mice increased in the number of their vertical rearings over the time span of the open-field trial $(P<0.0001$ by repeated measure ANOVA analysis). However, the rate of this increase was diminished in $P c m t 1-/-$ mice $(P<0.0001)$. No significant differences between $P c m t 1+/+$ and $P c m t 1+/-$ mice were observed. Error bars represent the standard error of the mean. 


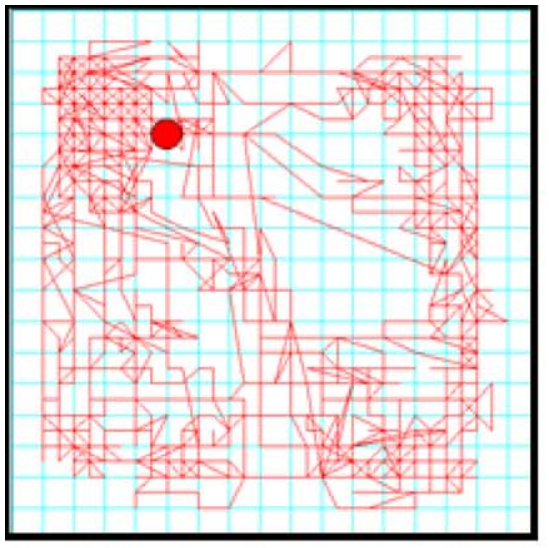

Pcmt1+/+

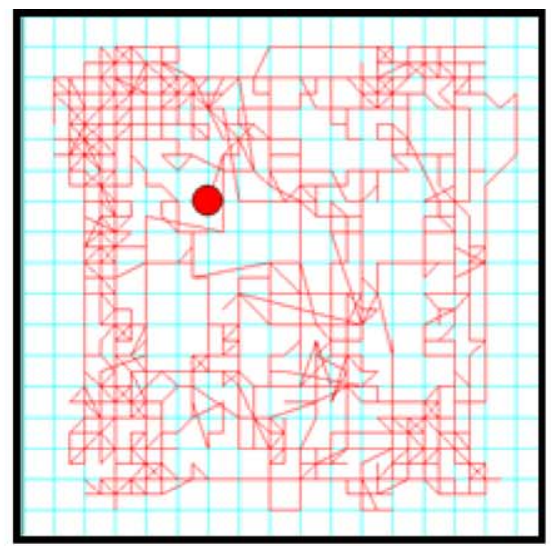

Pcmt1+/-

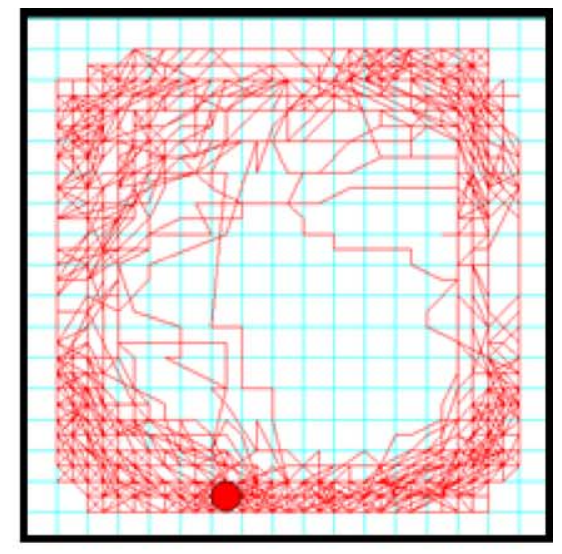

Pcrnt1-/-

Fig. 6. Pcmt1-/- mice exhibit thigmotaxic behavior in the open-field test. A typical movement trace of $P c m t 1-/-$ mice in open-field trials is compared to that of a $P c m t 1+/-$ and a $P c m t 1+/+$ mice. The thigmotaxic behavior was typical of the 30 Pcmt $1-/-$ mice tested, although a few displayed patterns normal exploration patterns as seen with the $P c m t 1+/-$ and a $P c m t 1+/+$ mice. We did not observe an thigmotaxic behavior in the $41 P c m t 1+/-$ mice or in the 22 Pcmt $1+1+$ mice tested.

experiments was due to this relative increase of AdoMet over AdoHcy. We approached this question by asking if mice maintained on a low-folate/antibiotic diet designed to perturb one-carbon metabolism and previously shown to increase plasma total homocysteine levels (B. Shane, personal communication) would also alter brain AdoHcy and potentially the AdoMet/AdoHcy ratio. As shown above in Fig. 1, Pcmt1-/- mice can be maintained on such a low-folate diet and in fact survive marginally better than those on a standard chow diet. We confirmed that plasma Hcy levels were significantly elevated in our mice fed the diet (Fig. 8). The extent of the elevation varied greatly among individual mice, but no differences in Pcmt1-/-, Pcmt1+/-, and $P c m t 1+/+$ mice were seen (data not shown). To demonstrate that the low-folate diet was the causal factor, one group of low-folate mice was tested and then placed on a regular

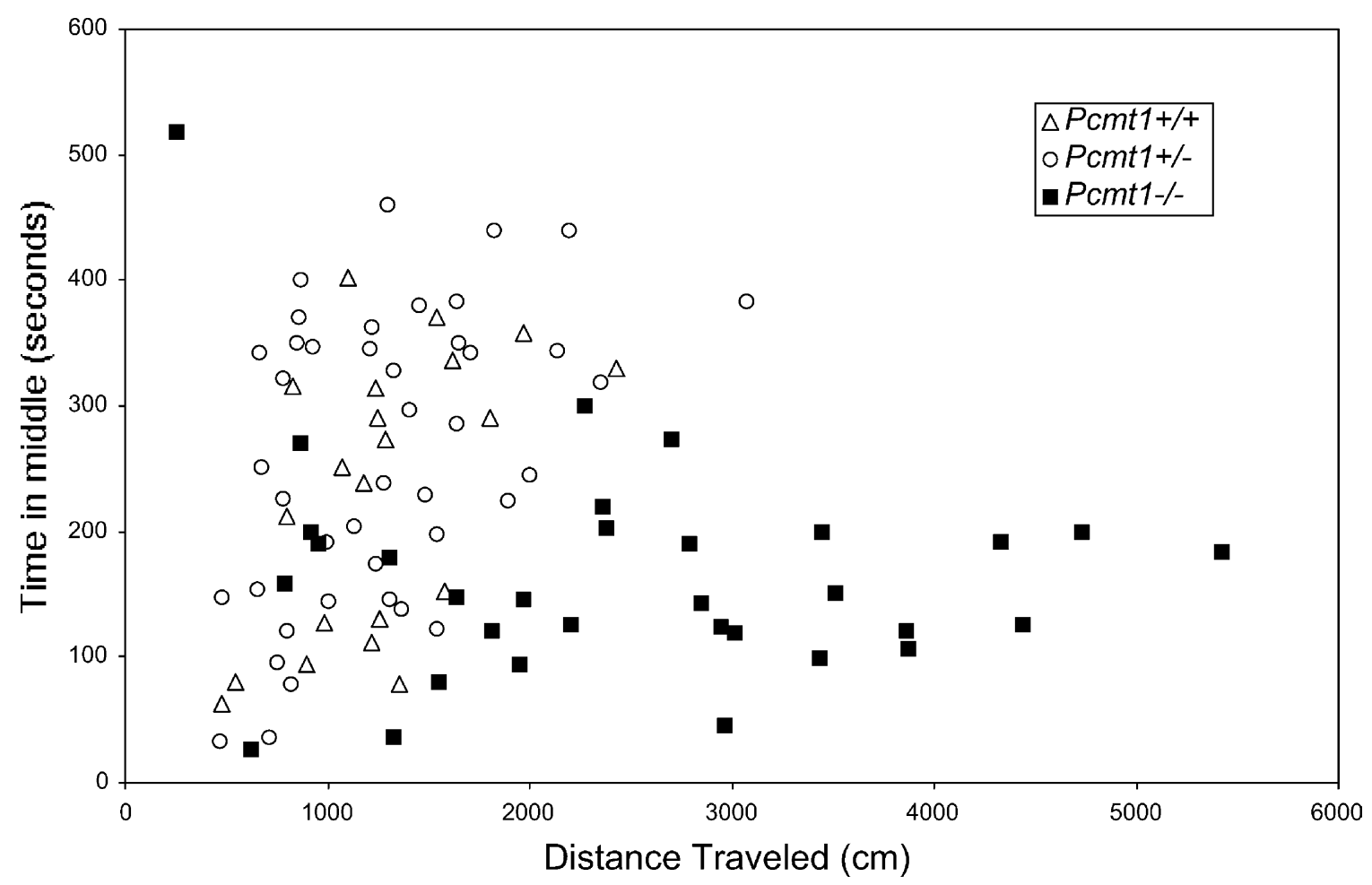

Fig. 7. Quantitative analysis of the thigmotaxic behavior of $P c m t 1-/-$ mice in comparison with $P c m t 1+/-$ and $P c m t 1+/+$ in the open-field test. The total distance traveled is plotted again the time that the mice spent in the center of the open field (total time was $600 \mathrm{~s}$ ). The center was defined as an eight by eight inch square in the middle of the open field. Each point represents an individual mouse. 


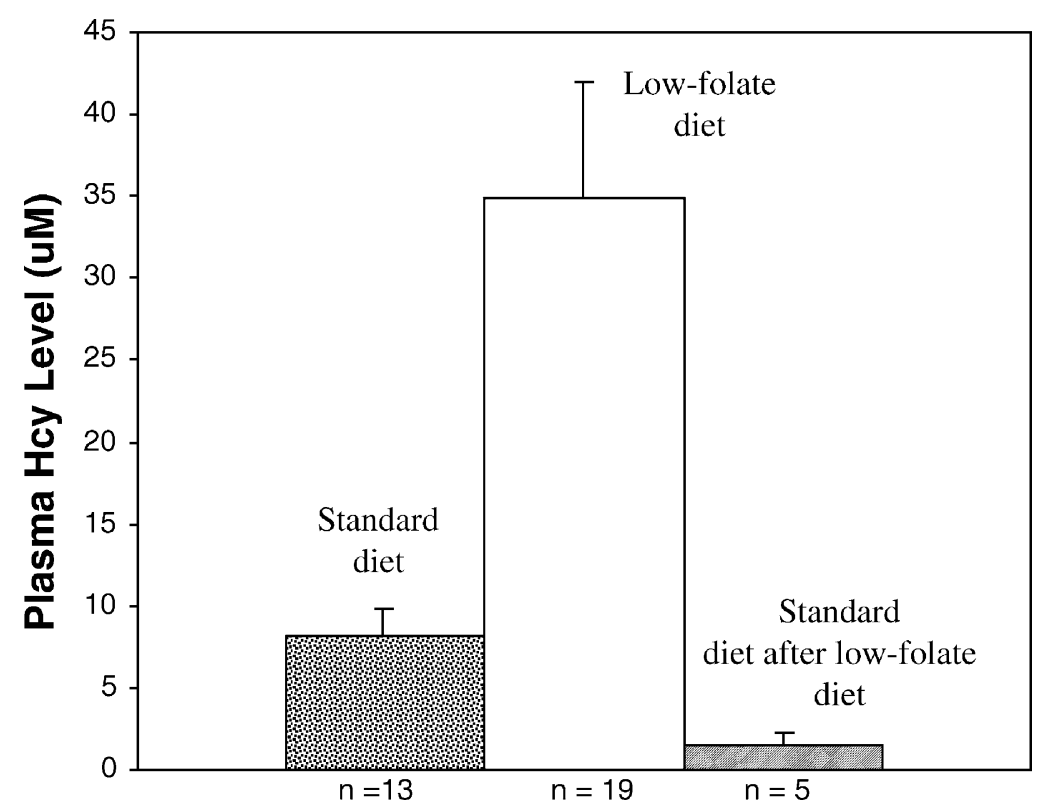

Fig. 8. Plasma total homocysteine levels increase in mice on a low-folate diet. Plasma total homocysteine was measured in samples from mice of varied genotypes and of ages ranging from 40 to 100 days. Mice were either kept on the standard diet or on the low-folate diet described in Section 2 from the time of weaning. An additional group of mice was kept on the low-folate diet from weaning to 40 days, and then shifted to the standard diet for 12 days before assay. The number of mice tested is indicated at the bottom of each bar. The standard error of the mean is indicated by the error bars.

diet. Plasma Hcy levels were re-measured 12 days later and showed no variance from the non-diet controls (Fig. 8).

Direct measurements of AdoMet and AdoHcy in mouse brain extracts were then performed (Fig. 9). We show here that animals of all three genotypes have lower AdoMet/ AdoHcy levels on the low-folate diet than heterozygotes and wild-type mice have on the standard diet, and are especially lower than those previously observed for $P c m t 1-/-$ mice on a standard diet (5). Thus, we have been successful in altering the AdoHcy/AdoMet ratio in brain. We then tested mice with such altered metabolite ratios on the rotorod apparatus. We found a similar improved performance with the knockout animals as seen when mice were maintained on a standard diet (Fig. 10; compare with Fig. 2). We also observed

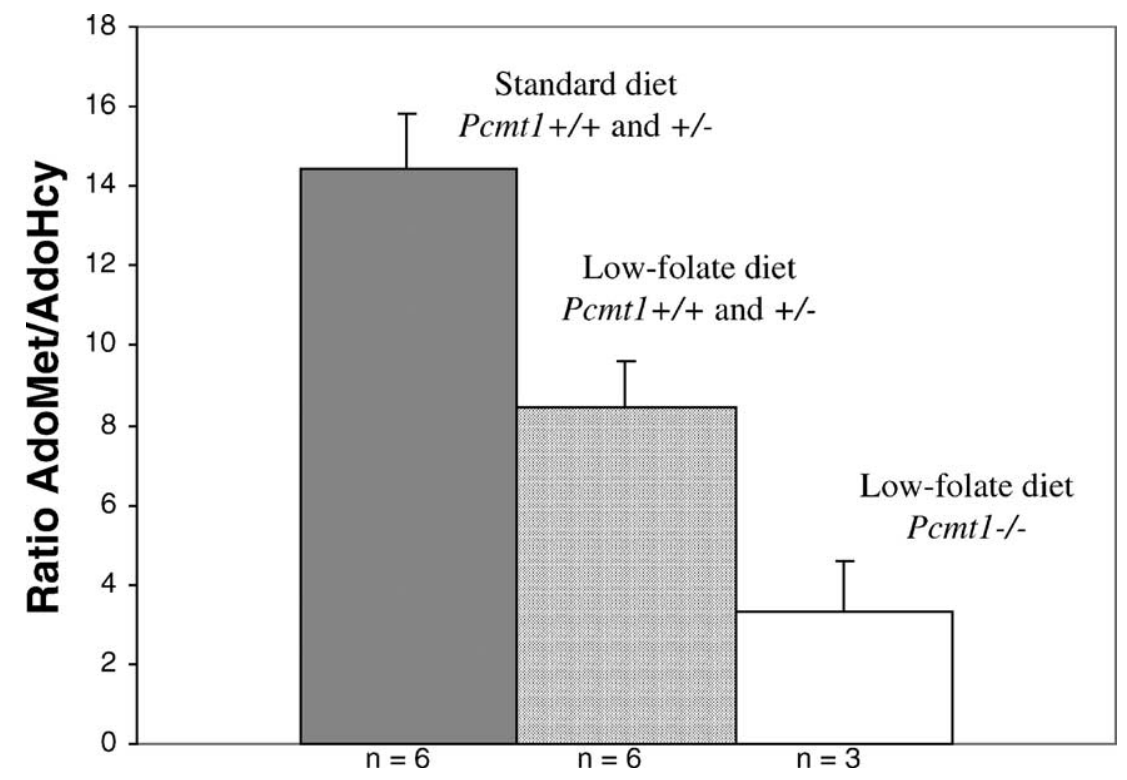

Fig. 9. Low-folate diet results an alteration of the brain AdoMet/AdoHcy ratio. Brain AdoMet and AdoHcy levels were measured using HPLC analysis. All mice were tested at 50 days of age. Mice were either on the standard diet or on the low-folate diet as described in Section 2 . The genotype(s) of each group is indicted in above the bar and the number of mice tested is indicated at the bottom of the bar. Error bars equal standard error of the mean. The difference between the ratio for the mixture of heterozygotes and wild-type mice on the standard and low-folate diets is significant $(P<0.01)$, as is the difference between the knockout mice on the low-folate diet and the mix of genotypes on the standard diet $(P<0.001)$. 


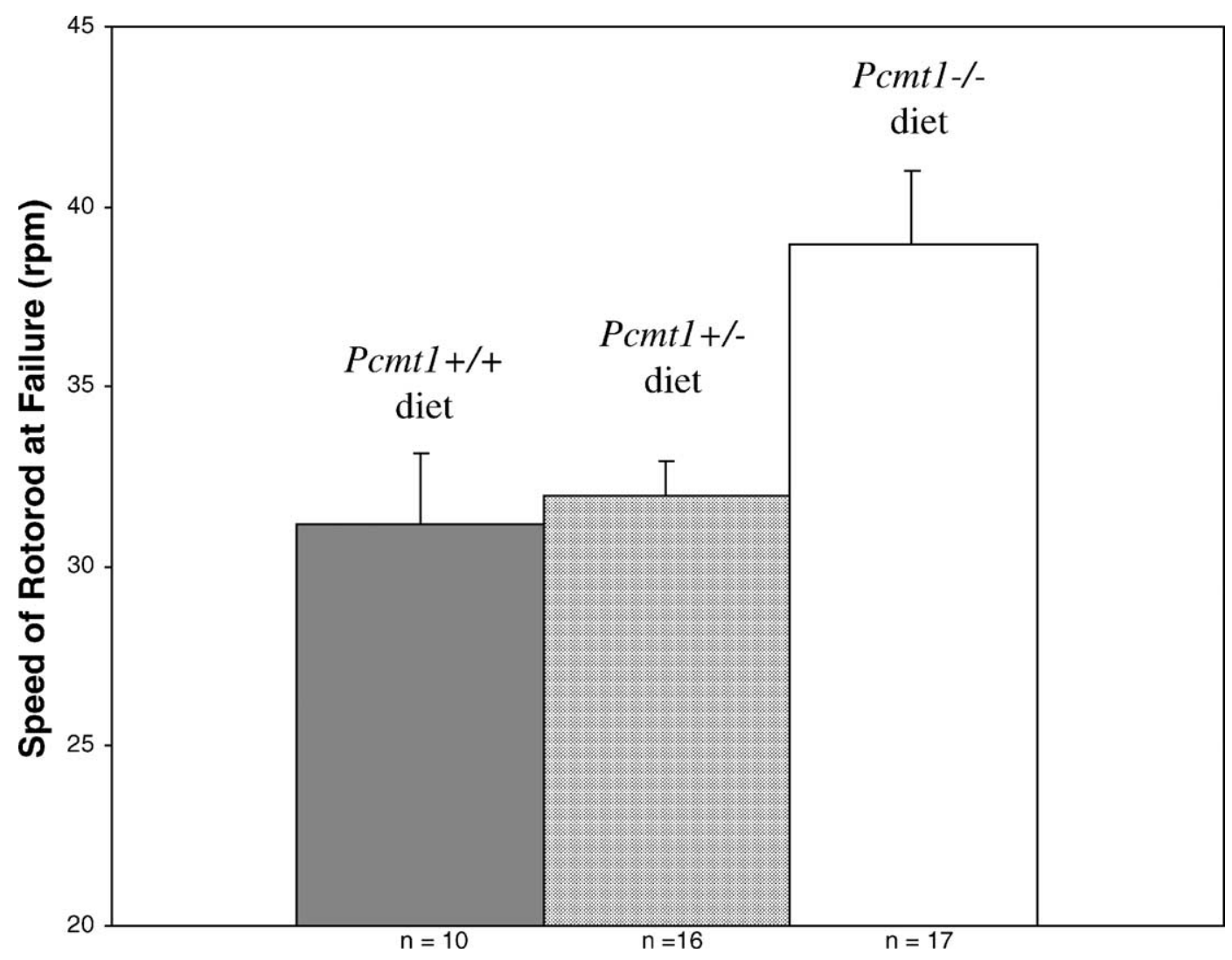

Fig. 10. Pcmt1-/- mice on a low-folate diet also demonstrate improved coordination on the accelerating rotorod. The effects of the diet on rotorod performance were assessed. All mice tested were naïve between 28 and 48 days of age and were on a low-folate diet from weaning as described in Section 2. Values from the three consecutive rotorod trials for each mouse were averaged to give one single score. The number of mice in each group is indicated below the graph. Error bars equal the standard error of the mean. The difference between the value for the $P c m t 1-/-$ mice and the group of $P c m t 1+/-$ and $P c m t 1+/+$ mice is significant $(P<0.001)$.

Table 2

Open-field behavior of wild-type and protein-repair-deficient mice maintained on a low-folate diet ${ }^{\mathrm{a}}$

\begin{tabular}{|c|c|c|c|}
\hline \multirow{2}{*}{$\begin{array}{l}\text { Measure of activity } \\
\text { in a } 1 \text {-min period }\end{array}$} & \multicolumn{3}{|l|}{ Mouse genotype } \\
\hline & $\begin{array}{l}\text { Wild-type } \\
\text { Pcmt } 1+/+(n=11)\end{array}$ & $\begin{array}{l}\text { Heterozygote } \\
\text { Pcmt } 1+/-(n=17)\end{array}$ & $\begin{array}{l}\text { Repair-deficient } \\
\text { Pcmt } 1-/-(n=16)\end{array}$ \\
\hline Average moving velocity $(\mathrm{cm} / \mathrm{s})$ & $29.4 \pm 1.8$ & $27.5 \pm 1.8$ & $25.3 \pm 0.8$ \\
\hline Ambulatory episodes & $9.9 \pm 1.1$ & $10.2 \pm 0.5$ & $14.0 \pm 1.4^{\mathrm{b}}$ \\
\hline Distance traveled $(\mathrm{cm})$ & $180 \pm 20$ & $184 \pm 20$ & $356 \pm 50^{c}$ \\
\hline Vertical rearings & $25.8 \pm 3.4$ & $25.5 \pm 2.2$ & $18.3 \pm 2.5^{\mathrm{b}}$ \\
\hline Stereotypic counts & $177 \pm 12$ & $176 \pm 10$ & $148 \pm 10^{\mathrm{b}}$ \\
\hline
\end{tabular}

\footnotetext{
${ }^{a}$ Values are given \pm standard error of the mean.

${ }^{\mathrm{b}} P$-value $<0.05$, when compared to wild-type and heterozygotes.

${ }^{\mathrm{c}} P$-value $=0.0002$, when compared to wild-type and heterozygoes.
}

similar increases in distance traveled and ambulatory episodes in the open-field test for Pcmt1-/- mice maintained on the low-folate diet compared to their Pcmt1+Iand Pcmt $1+/+$ littermates on the same diet (Table 2, Fig. 11; compare to Table 1, Fig. 4). Interestingly, we also detected a general increase in most of the open-field parameters when mice of a given genotype were placed on the low-folate diet; the reason for these changes are not clear at present. In any case, these results indicate that the improved performance in the rotorod test and the increased hyperactivity in the open-field test for the Pcmt1-/- mice does not appear to be a function of altered brain AdoMet and AdoHcy levels.

\section{Discussion}

The availability of protein-repair-deficient $P c m t 1-/-$ knockout mice has provided a unique epileptic model with 


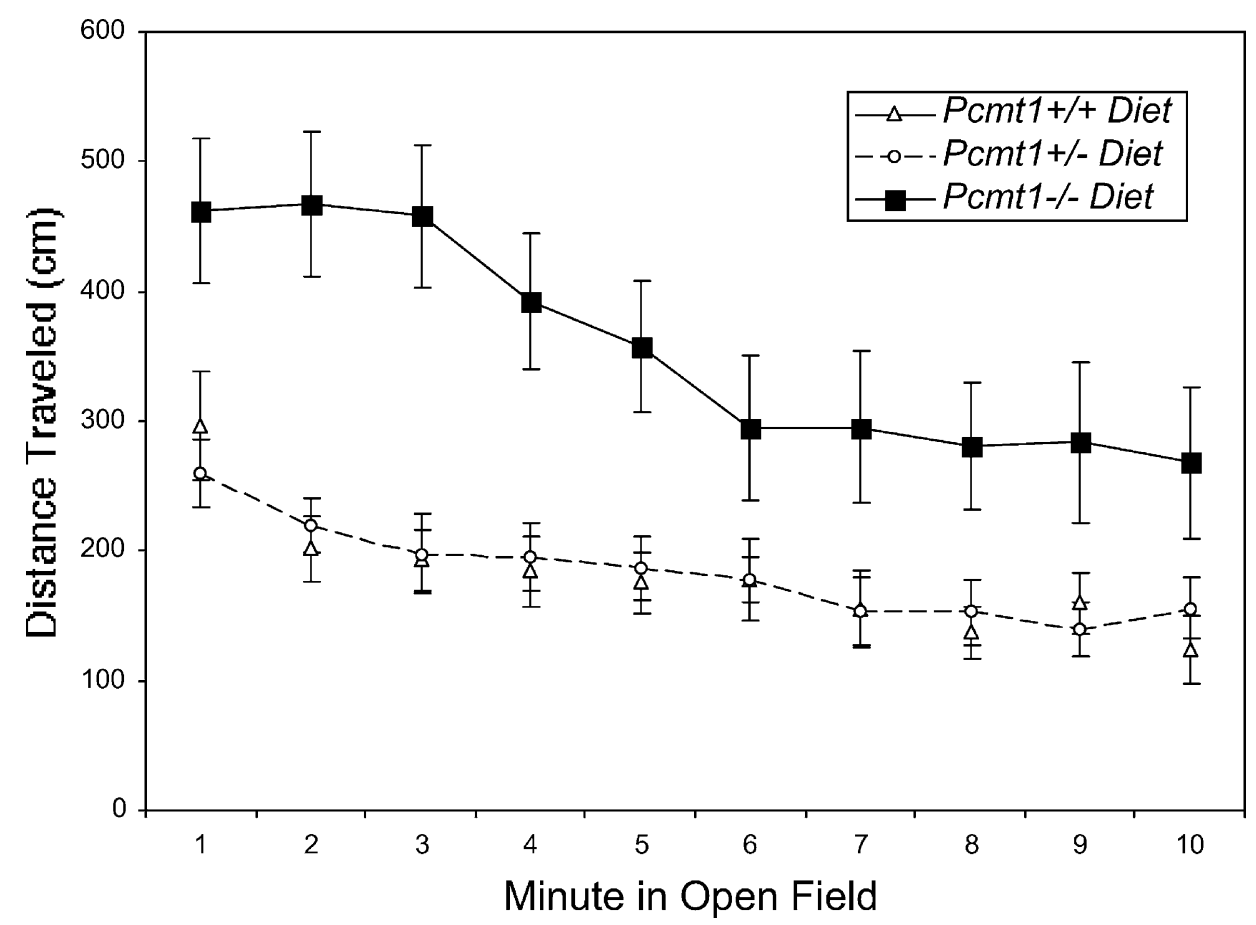

Fig. 11. Hyperactivity in open-field trials for mice on a low-folate diet. All mice tested were naïve and between 28 and 48 days of age after being on a low-folate diet from weaning as described in Section 2. The distance traveled in each minute of the 10-min open-field exposure is shown. The number of mice tested were 22, 41, and 31 for the Pcmt1+/+, Pcmt1+/-, and Pcmt1-/- genotypes, respectively. The error bars represent the standard error of the mean.

additional significance for understanding neurodegenerative disorders that may result from the accumulation of damaged proteins $[12,15,18,30]$. Our study was aimed at quantifying the severity of neural impairment in Pcmt1-/- mice in non-stressful behavioral assays. We have shown here that Pcmt1-/ - mutants display significant hyperactivity when placed in a novel environment accompanied by deficits in exploration behavior expressed as a thigmotaxic pattern of movement. These open-field results suggest Pcmt1-/mice have a navigation defect when compared to their Pcmt $1+/+$ and Pcmt1+/- littermates. While control mice show trepidation initially in the open-field apparatus, this is followed by gradual increases in movement, vertical rearings, and center exploration. However, Pcmt $1-/-$ mice display a thigmotaxic hyperactivity using the chamber walls to define their movement and show significantly less of an increase in vertical rearings. They do, however, begin to habituate to their environment (in terms of the distance traveled) so do appear to be capable of spatial learning. This defect in exploration was also underlie to some extent the decreased performance of Pcmtl-I- mice seen previously in the Morris water maze, where the mice also display a thigmotaxic swimming behavior [12]. The abnormal open-field behavior is induced at approximately 35 days of age, a time correlated with the onset of their epileptic disorder, isoaspartyl accumulation, and a change in the AdoMet/AdoHcy ratio [5,16,20,30]. The causal factor or factors for these events remain to be determined.
However, these Pcmt1-/- mice demonstrate enhanced function on the accelerating rotorod task. This was an unexpected result; we anticipated either a deficit or no difference between Pcmt1-/- mutants and their littermates. To our knowledge, this is the only example of an epileptic mouse model that displays improved motor coordination on this test. We are aware of at least two situations where genetic alteration of mice can result in improved performance on this type of test. Improved performance is seen in at least one experimental protocol for Ts65Dn mice that have three copies of a segment of chromosome 16 that corresponds to a large section of human chromosome 21 , where trisomy results in Down syndrome [11]. Improved performance is also seen in heterozygous mutant mice in the heregulin gene that encodes a ligand for two tyrosine kinase receptor signaling pathways [8]. Interestingly, these latter mice also demonstrate hyperactivity in the open-field test [8]. We are currently investigating what role Pcmt1 may play in the cerebellum.

Recently, it has been hypothesized that changes in the levels of AdoMet and AdoHcy may be responsible for some of the abnormalities observed in the Pcmt1-/- mutant mice [5]. In this study, we have shown that the abnormally high AdoMet/AdoHcy ratio previously seen in the Pcmt1-/ - mice can be significantly lowered when these animals are placed on a low-folate diet. However, we found that these mice behaved similarly on both the rotorod and the open-field tests as knockout mice on a standard diet, suggesting that an altered AdoMet/AdoHcy ratio is not the 
primary determinant of the behavior. The situation may be more complex because both AdoHcy and AdoMet have a number of actions in the brain that may or may not be related to their roles as substrate and product of transmethylation reactions. AdoHcy appears to have endogenous antiepileptic function [6] and AdoMet administration can induce apoptosis in PC12 cells [32], increase hydrogen sulfide production [4], induce Parkinson's disease like tremors when administered to mice [17], and act as an antidepressant [21].

The generation of the Pcmt1 knockout mouse was originally developed with the intention of being a useful model of protein damage accumulation in the aging process. However, the enzyme's importance in neurological function has created a unique epileptic model with implications in several neurodegenerative disorders. This study further elucidates Pcmt1's role in hippocampal function and reveals a new importance in cerebellar motor coordination as well. Thus far, neither isoaspartyl damage, progressive epilepsy, or altered AdoMet/AdoHcy ratios can be distinguished as the significant defect leading to the Pcmt1-/- mouse's abnormalities.

\section{Acknowledgements}

We are grateful to Drs. Matthew J. Sanders and Alcino J. Silva of the UCLA Behavioral Testing Core facility for expert advice on these experiments. We are especially grateful to Dr. Sanders for his assistance in setting up the experiments and in interpreting the results. Breeding pairs of mice were provided kindly by Christine Farrar. We thank Dr. Barry Shane of the University of California at Berkeley for providing information on the low-folate diet and its effect on plasma total homocysteine levels. We also thank Dr. Jonathan Lowenson and Kelley Banfield for their help with this work. We are grateful to Brian Young for his expert assistance with figure preparation. Finally, we express our gratitude to Drs. Yuying Tan and Robert Hoffman at Anticancer, Inc. (San Diego, CA) for their advice and for performing the homocysteine analyses. This work was supported by grants GM26020 and AG18000 from the National Institutes of Health.

\section{References}

[1] Allen PT, Poirier LA. Suppression by phenobarbital of ethionineinduced hepatocellular carcinoma formation and hepatic $S$-adenosylethionine levels. Carcinogenesis 1997;18:1103-7.

[2] Chavous DA, Hake LE, Lynch RJ, O'Connor CM. Translation of a unique transcript for protein isoaspartyl methyltransferase in haploid spermatids: implications for protein storage and repair. Mol Reprod Dev 2000;56:139-44.

[3] Clarke S. Aging as war between chemical and biochemical processes: protein methylation and the recognition of age-damaged proteins for repair. Aging Res 2003;2:263-85.

[4] Eto K, Kimura H. The production of hydrogen sulfide is regulated by testosterone and $S$-adenosyl-L-methionine in mouse brain. J Neurochem 2002;83:80-6.
[5] Farrar C, Clarke S. Altered levels of $S$-adenosylmethionine and $S$ adenosylhomocysteine in the brains of L-isoaspartyl D-Aspartyl; $O$ methyltransferase-deficient mice. J Biol Chem 2002;277:27856-63.

[6] Fonlupt P, Roche M, Andre AC, Cronenberger L, Pacheco H. SAdenosyl-L-homocysteine: 2. An anticonvulsant. Can J Physiol Pharmacol 1980;58:493-8.

[7] Geiger T, Clarke S. Deamidation isomerization and racemization at asparaginyl and aspartyl residues in peptides: succinimidelinked reactions that contribute to protein degradation. J Biol Chem 1987;262:785-94.

[8] Gerlai R, Pisacane P, Erickson S. Heregulin, but not ErbB2 or ErbB3 heterozygous mutant mice exhibit hyperactivity in multiple behavioral tasks. Behav Brain Res 2000;109:219-27.

[9] Gill MW, Schatz RA. The effect of diazepam on brain levels of $S$ adenosyl-1-methionine and $S$-adenosyl-L-homocysteine: possible correlation with protection from methionine sulfoximine seizures. Res Commun Chem Pathol Pharmacol 1985;50:349-63.

[10] Hsu YR, Chang WC, Mendiaz EA, Hara S, Chow DT, Mann MB, et al. Selective deamidation of recombinant human stem cell factor during in vitro aging: isolation and characterization of the aspartyl and isoaspartyl homodimers and heterodimers. Biochemistry 1998;37:2251-62.

[11] Hyde LA, Crnic LS, Pollock A, Bickford PC. Motor learning in Ts65Dn mice, a model for Down syndrome. Dev Psychobiol 2001;38:33-45.

[12] Ikegaya Y, Yamada M, Fukuda T, Kuroyanagi H, Shirasawa T, Nishiyama N. Aberrant synaptic transmission in the hippocampal CA3 region cognitive deterioration in protein-repair enzyme-deficient mice. Hippocampus 2001;11:287-98.

[13] Johnson BA, Langmack EL, Aswad DW. Partial repair of deamidation-damaged calmodulin by protein carboxyl methyltransferase. J Biol Chem 1987;262:12283-7.

[14] Johnson BA, Murray Jr ED, Clarke S, Glass DB, Aswad DW Protein carboxyl methyltransferase facilitates conversion of atypical L-isoaspartyl peptides to normal L-aspartyl peptides. J Biol Chem 1987;262:5622-9.

[15] Kim E, Lowenson JD, Clarke S, Young SG. Phenotypic analysis of seizure-prone mice lacking L-isoaspartate D-aspartate; O-methyltransferase. J Biol Chem 1999;274:20671-8.

[16] Kim E, Lowenson JD, MacLaren DC, Clarke S, Young SG. Deficiency of a protein-repair enzyme results in the accumulation of altered proteins retardation of growth fatal seizures in mice. Proc Natl Acad Sci USA 1997;94:6132-7.

[17] Lamango NS, Nesby RA, Charlton CG. Quantification of $S$ adenosylmethionine-induced tremors: a possible tremor model for Parkinson's disease. Pharmacol Biochem Behav 2000;65:523-9.

[18] Lanthier J, Bouthillier A, Lapointe M, Demeule M, Beliveau R, Desrosiers RR. Down-regulation of protein L-isoaspartyl methyltransferase in human epileptic hippocampus contributes to generation of damaged tubulin. J Neurochem 2002;83:581-91.

[19] Lowenson JD, Clarke S. Recognition of D-aspartyl residues in polypeptides by the erythrocyte L-isoaspartyl/D-aspartyl protein methyltransferase: implications for the repair hypothesis. J Biol Chem 1992;267:5985-95.

[20] Lowenson JD, Kim E, Young SG, Clarke S. Limited accumulation of damaged proteins in 1-isoaspartyl D-aspartyl; $O$-methyltransferasedeficient mice. J Biol Chem 2001;276:20695-702.

[21] Mischoulon D, Fava M. Role of $S$-adenosyl-L-methionine in the treatment of depression: a review of the evidence. Am J Clin Nutr 2002;76:1158S-61S.

[22] Nabuchi Y, Fujiwara E, Kuboniwa H, Asoh Y, Ushio H. The stability degradation pathway of recombinant human parathyroid hormone: deamidation of asparaginyl residue peptide bond cleavage at aspartyl asparaginyl residues. Pharm Res 1997;14:1685-90.

[23] Reissner KJ, Aswad DW. Deamidation and isoaspartate formation in proteins: unwanted alterations or surreptitious signals? Cell Mol Life Sci 2003;60:1281-95. 
[24] Roher AE, Lowenson JD, Clarke S, Wolkow C, Wang R, Cotter RJ, et al. Structural alterations in the peptide backbone of beta-amyloid core protein may account for its deposition stability in Alzheimer's disease. J Biol Chem 1993;268:3072-83.

[25] Shimizu T, Ikegami T, Ogawara M, Suzuki Y, Takahashi M, Morio H. Transgenic expression of the protein-L-isoaspartyl methyltransferase PIMT gene in the brain rescues mice from the fatal epilepsy of PIMT deficiency. J Neurosci Res 2002;69:341-52.

[26] Swann JW, Al-Noori S, Jiang M, Lee CL. Spine loss and other dendritic abnormalities in epilepsy. Hippocampus 2000;10:61725.

[27] Tan Y, Tang L, Sun X, Zhang N, Han Q, Xu M, et al. Totalhomocysteine enzymatic assay. Clin Chem 2000;46:1686-8.

[28] Tomiyama T, Asano S, Furiya Y, Shirasawa T, Endo N, Mori H. Racemization of Asp23 residue affects the aggregation proper- ties of Alzheimer amyloid beta protein analogues. J Biol Chem 1994;269:10205-8.

[29] Ubeda N, Alonso-Aperte E, Varela-Moreiras G. Acute valproate administration impairs methionine metabolism in rats. J Nutr 2002; 132:2737-42.

[30] Yamamoto A, Takagi H, Kitamura D, Tatsuoka H, Nakano H, Kawano $\mathrm{H}$, et al. Deficiency in protein L-isoaspartyl methyltransferase results in a fatal progressive epilepsy. J Neurosci 1998;18:2063-74.

[31] Young AL, Carter WG, Doyle HA, Mamula MJ, Aswad DW. Structural integrity of histone $\mathrm{H} 2 \mathrm{~B}$ in vivo requires the activity of protein L-isoaspartate $O$-methyltransferase a putative protein repair enzyme. J Biol Chem 2001;276:37161-5.

[32] Zhao WQ, Williams Z, Shepherd KR, Reuben JS, Lee ES. $S$ Adenosyl-methionine-induced apoptosis in PC12 cells. J Neurosci Res 2002;69:519-29. 